\title{
Broadening Social Risk Management: Risks, Rights and the Chronic Poor
}

\author{
Bruce Guenther, Karishma Huda and Ian Macauslan
}

\begin{abstract}
Social Risk Management (SRM) has had such influence on social policy in the South that Holzmann et al. (2003: 4-5) have been moved to write that 'it is no exaggeration to say that the new SRM framework has become the reference point for the thinking about [social protection] in a development context'. Given this significance, it is perhaps surprising that rather few critiques have been articulated. Although SRM clearly represents an important and useful advance for social protection, we present three recommendations for further improvement.
\end{abstract}

\section{Broadening risk}

The Cambridge Advanced Learner's Dictionary defines risk as 'the probability of something bad happening.'. In SRM, the set of 'bad things' is limited to individual income shocks. However, this underestimates the complexity of the relationship between shocks and decreases in individuals' welfare. For example, identical shocks may lead to different welfare effects for different individuals, even if they have the same endowment set, because individuals attach different values to the capabilities affected by the shock.

Moreover, although income is defined (1999: 4) 'in the widest possible' way to include concerns about services, many 'bad things' that people care about are not income shocks. Many different sorts of shocks do of course affect individuals' income and income potential, but reducing all categories of risk to their effects on income misunderstands what risks people are actually concerned with. This would lead to claiming that the death of a family member is important primarily because it may result in a reduction in the household's income-earning potential through the elimination of an income-earner. This interpretation dehumanises and instrumentalises risk management.
}

Greater clarity about the conceptual framework for choice under uncertainty would make gaps more explicit in the SRM framework. Once we recognise that: (1) individuals care about a wide range of bad things and not just low or falling income;

(2) individuals value the same shocks differently; and (3) individuals attach different subjective probabilities to shocks, it becomes clear that SRM is concerned with a rather small category of factors that influence behaviour. The outcomes of critically important choices between, for instance, manually de-mining household land to farm it and decreasing food intake will vary enormously between decisionmakers and for the same decision-maker, depending on a wide range of changing psychological, economic and social conditions. The SRM framework, by (seemingly) focusing on objective, absolute, individual, income risk, deals poorly with these choices.

\section{Chronic poverty}

In addition, the SRM conceptual framework, in focusing on shocks, diverts attention from underlying processes or events that generate shocks. Is this appropriate? Devereux and Sabates-Wheeler (2004: 6) argue that vulnerability (defined in SRM as the increased probability of becoming or remaining income poor) ${ }^{2}$ should be 'conceptualised as emerging from and embedded in the socio-political context'. While social protection in the SRM framework is defined to include interventions that 'provide support to the critically poor' (World Bank 2001: 9), the needs of the chronically poor - those remaining poor over long periods - are not explicitly addressed. In policy terms, SRM leads to interventions that focus on transitory income shocks rather than on structural determinants of poverty. 
Research from Bangladesh indicates that many people are trapped in a cycle of deprivation due to a combination of poor health, lack of education, fractured families, as well as inadequate infrastructure, poor social networks, and scarce employment opportunities. This combination of structural economic and sociopolitical deprivation of the chronically poor is captured well in the following quote: 'life for us is like a worn-out blanket - you go on stitching only to discover new holes' (Matin and Halder 2002: 3).

In Bangladesh, the Bangladesh Rural Advancement Committee's (BRAC) Challenging the Frontiers of Poverty Reduction/Targeting the Ultra Poor Programme (CFPR/TUP) is a multi-pronged social protection scheme designed to provide the extreme poor with assets for entrepreneurial use, legal as well as health services, a consumption stipend and social links with village elites. It exemplifies two crucial points about the chronically poor: (1) they face complex and intertwined roots of poverty at the family and individual levels, which must be tackled for social protection instruments to have any lasting effect; and (2) they do not face only income risk that market-based interventions can solve alone, but various 'social risks' that affect production both directly and indirectly.

The CFPR/TUP approach would broaden the understanding, in the SRM framework, of social protection 'as public measures to provide income security to the population' (Holzmann et al. 2003: 2). In the CFPR/TUP, effective social protection requires both a promotional component that increases the incomes, productivity or employment prospects of poor people, and a protective component that reduces their vulnerability to destitution, hunger, social and political marginalisation (Matin and Halder 2002). Income security is not attained via standalone saving mechanisms or insurance programmes Rather, a combination of 'pushing down' (reaching the poorest sectors of the population that traditional development schemes bypass) and 'pushing out' (providing services that have a social development agenda at their core) deals with the varied and often subjective risks that the extreme poor face.

We would like to see the SRM framework incorporate both these components - thereby including the extreme poor and the complex deprivations they endure.

\section{The right to social protection}

In part, the SRM model's reluctance to address the needs of the chronic poor flows from the framework's emphasis on risk mitigation, as opposed to rights and entitlements. While SRM recognises the importance of redistribution and improving equity, it primarily highlights the 'productive' side of social protection - as a tool for mitigating household risk - in contrast to a framework based on 'entitlement' that emphasises state obligations to provide for citizens' basic needs. ${ }^{3}$

In an important advance from early formulations of SRM, Holzmann and Kozel's article (this IDS Bulletin) recognises that 'the support of SRM instruments for all is fully consistent with the human rights-based approach and the call for minimum provisions'. However, a rights-based understanding of social protection remains peripheral within the SRM framework. Constituting social protection squarely within a rights framework is essential not only in guaranteeing basic provisions for the chronic poor, but such a framework is also necessary for securing the long-term political sustainability of social protection.

Joshi and Moore (2000) argue that the successful performance of the Maharashtra Employment Guarantee Scheme (MEGS) in India is due in part to the centrality of rights. Guaranteeing state employment through the MEGS allows citizens to mobilise around their right to employment. 'It is the entitlement to employment that limits bureaucratic discretion and ensures that, to a substantial degree, MEGS opportunities really are self-targeted on the poor' (Joshi and Moore 2000: 27).

We agree with Holzmann and Jorgensen's (1999 and 2000) emphasis on ensuring the political sustainability of social protection. Recent research on the Productive Safety Nets Programme (PSNP) in Ethiopia indicates that while highlighting the productive side of the PSNP may constitute a persuasive case for social protection, the long-term political sustainability of the programme is threatened by the Government of Ethiopia's lack of commitment to social protection as an entitlement (SabatesWheeler et al. 2007). Grounding social protection within a rights framework allows citizens and civil society to mobilise around the right to social protection, helping to ensure long-term sustainability. 


\section{Conclusion}

This article has suggested that, although the SRM framework is extremely important in its centralisation of risk and vulnerability in development policy, its scope of risk and solutions to mitigating those risks need further expansion. Our recommendations can be summarised as:

- not placing income risks at the centre, and all other forms of risk on the periphery

\section{Notes}

1 Online. Available at http://dictionary.cambridge.org/ define. asp? key $=68183 \&$ dict $=$ CALD

2 Holzmann and Jorgensen (1999: 6). More recent World Bank work on vulnerability outlines four definitions but operationalises vulnerability largely with this definition (Holzmann et al. 2003: 10-12).

\section{References}

Devereux, S. and Sabates-Wheeler, R. (2004) Transformative Social Protection, IDS Working Paper 232, Brighton: IDS

Holzmann, R., and Jorgensen, S. (2000) Social Risk Management: A New Conceptual Framework for Social Protection, and Beyond, Social Protection Discussion Paper Series 0006, Washington DC: The World Bank

Holzmann, R., and Jorgensen, S. (1999) Social Protection as Risk Management: Conceptual Underpinnings for the Social Protection Strategy Paper, Social Protection Discussion Paper Series 9904, Washington DC: The World Bank

Holzmann, R., Sherburne-Benz, L. and Tesliuc, E. (2003) Social Risk Management: The World Bank's Approach to Social Protection in a Globalising World, Washington DC: The World Bank
- developing an explicit focus on structural determinants of risk, addressing the chronically poor who face a complex set of sociopolitical deprivations

- incorporating a rights-based understanding of social protection.

Understandings of household risk and the concept of social protection are evolving, both at the World Bank and elsewhere. We hope this article can make a modest contribution to that ongoing discussion.

3 This point is related to an earlier criticism by Devereux and Sabates-Wheeler (2004), who highlight the limited role of public service provision envisaged in SRM.

Joshi, A. and Moore, M. (2000) The Mobilising Potential of Anti-Poverty Programmes, IDS Discussion Paper 374, Brighton: IDS

Matin, I. and Halder, S. (2002) 'Combining Targeting Methodologies for Better Targeting of the Extreme Poor: Some Preliminary Findings from BRAC's CFPR/TUP program', unpublished BRAC research report, mimeo, Dhaka: Bangladesh Rural Advancement Committee (BRAC)

Sabates-Wheeler, R., Davies, M., Guenther, B. and Macauslan, I. (2007) Social Transfers and Policy Influence: DFID and the Politics of Influencing, DfID Social Transfers Evaluation. Brighton: IDS

World Bank (2001) Social Protection Sector Strategy: From Safety Net to Springboard, Washington DC: The World Bank 